\title{
MÚSICA, FANTASIA E TEMPORALIDADE NA FENOMENOLOGIA DE HUSSERL ${ }^{1}$ Vanessa Fontana (UNIOESTE) ${ }^{2,3}$ \\ fontanessa@yahoo.com.br
}

Resumo: $\mathrm{O}$ artigo analisa a questão da música nas obras de Edmund Husserl. Entre as obras mais importantes para o tema estão as Lições para uma fenomenologia da consciência interna do tempo publicada em 1905 e o volume XXIII da husserliana sob o título de: Fantasia, consciência de imagem e memória. Da fenomenologia das presentificações intuitivas. Textos póstumos (1898-1925). O artigo faz uma crítica às leituras limitadoras da compreensão da fantasia, modo de consciência que gere a arte musical.

Palavras-chave: temporalidade; fantasia; música.

\section{INTRODUÇÃO}

O trabalho apresenta uma relação entre a música, a temporalidade e a fantasia na fenomenologia de Edmund Husserl. Trata-se de analisar a música através da intencionalidade da fantasia e mostrar como a temporalidade se dá no decorrer da análise acerca da arte especifica da música. Para trabalhar tal temática é preciso deixar claro, que o melhor caminho é assumir como premissa a fantasia como modo próprio de intencionar a obra de arte, em destaque a música. Defende-se a importância da fantasia como forma privi-

\footnotetext{
${ }^{1}$ Recebido: 15-07-2020/ Aceito: 26-01-2021/ Publicado online: 15-04-2021.

2 É professora na Universidade Estadual do Oeste do Paraná (UNIOESTE), Cascavel, PR, Brasil.

${ }^{3}$ ORCID: https://orcid.org/0000-0001-9027-9671.
} 
legiada da consciência transcendental, "Eu puro ${ }^{4}$, e de seu desprendimento da percepção, ou seja, a fantasia está num modo intencional específico e distinto da percepção. Não há aqui "recaída" da fantasia na percepção, a fantasia não depende da percepção, o campo de experiência da fantasia é muito mais vasto. A tese de fundo é dizer que a fantasia possui um privilégio metodológico na fenomenologia de Husserl, mesmo ao afirmar a percepção como base da consciência temporal, esta não se dá apenas no presente, mas depende necessariamente das relações de presentificações ${ }^{5}$ para se estabelecer como fluxo temporal.

A fantasia é uma grande novidade da fenomenologia de Husserl para a história da filosofia, que antes queria restringi-la ao conhecimento falso, duvidoso e secundário da

\footnotetext{
${ }^{4} \mathrm{O}$ conceito de Eu puro ou consciência transcendental aparece de forma explícita nas Ideias I de 1913, ano que Husserl reedita as Investigações Lógicas cuja primeira edição ocorreu em 1900. Na primeira edição das Investigações Husserl nega um eu unificador dos atos da consciência, mas no prefácio à segunda edição de 1913 ele explica: "Não aprovo mais a contestação ao eu puro; no entanto, deixei ficar, sob uma forma abreviada e formalmente melhorada, as afirmações a esse respeito..." (HUSSERL, 2014, p. XIX) O trecho ao qual ele se refere está na V investigação § 12 e diz o seguinte: "Se, agora se atenta na vivência de ato, então parece que o eu se refere necessariamente ao objeto através do ato ou no ato e, em última análise, poder-se-ia ficar inclinado a inserir um eu em cada ato, enquanto ponto de unidade essencial por todo lado idêntico. Com isso, regressaríamos, agora, à assunção, antes recusada, de um eu puro como centro de referência." (HUSSERL, 2007, p. 411). Segundo Pedro Alves: "...as Investigações haviam permanecido, apesar de tudo, ainda aprisionadas numa caracterização estritamente psicológica da consciência." (ALVES 2003, p. 273). Assim, a melhor definição da consciência como eu puro ou consciência pura (transcendental) vem de Ideias I: "Prosseguimos, primeiro, mostrando diretamente e, uma vez que o ser a mostrar não é senão aquele que, por fundamentos essenciais, designamos como 'vividos puros', como 'consciência pura', que tem, de um lado, seus puros 'correlatos de consciência' e, de outro, seu 'eu puro'[...]” (HUSSERL, 2006, p. 83).

${ }^{5}$ As presentificações (Vergegenwärtigungen) são os atos modificados da consciência temporal do presente, a qual se caracteriza pela consciência perceptiva. Na terminologia do tempo a percepção se define como presentação (Gegenwärtigung). As presentificações são todos os outros atos da consciência, como: fantasia, memória, atenção. Sobre isso diz Husserl: "Mas a presentificação pode ser recordar, atentar, e outras semelhantes. Ou também a simples fantasia". (HUSSERL, 2002, p. 295) No original: "Vergegenwärtigung kann aber sein Erinnerung, Erwartung u. dgl. Oder, blosse Phantasie". (HUSSERL, 1980, p. 290).
} 
consciência. O filósofo e discípulo Jean-Paul Sartre reconhece a importância de Husserl na renovação da concepção de imaginação e imagem: "[...] Husserl liberou o mundo psíquico de um peso grande e suprimiu quase todas as dificuldades que obscureciam o problema clássico das relações da imagem com o pensamento". (SARTRE, 1987, p.101) Como o pai da fenomenologia fez essa mudança e liberou a filosofia do erro da imagem signo? Através da intencionalidade, ou seja, da teoria intencional da consciência, a qual diz ser toda consciência, consciência de algo. Há sempre a referência a algo fora da consciência, os noemas ${ }^{6}$ não estão na consciência. Como bem diz Sartre: "Ao contrário, Husserl começa por colocar a árvore fora de nós". (SARTRE,

\footnotetext{
${ }^{6} \mathrm{O}$ termo noema e também o termo noese se referem à vivência intencional. De um lado, a noese trata dos atos intencionais da consciência e se refere ao polo da subjetividade (Perceber, fantasiar, memorar), de outro lado, o noema trata dos correlatos intencionais da consciência e se refere ao polo da objetividade (Percebido, fantasiado, memorado). Como explica Husserl em Idéias I toda vivência intencional tem seu sentido objetivo. Para toda vivência noética existe um correlato noemático, ou seja, não existe uma consciência voltada para, sem um sentido correlato eidético referido. (HUSSERL, 2006) Dagfinn Follesdal no seu artigo intitulado: Husserl's Notion of Noema explica a importância desse conceito para pensar a fenomenologia. Ele diz: "A noção de noema de Husserl, portanto, é uma noção chave na sua teoria da intencionalidade e, desse modo, em sua fenomenologia. De acordo com Husserl, uma compreensão própria e adequada das distinções conectadas com o noema "é da maior importância para a fenomenologia e decisivo para dar-lhe uma base certa (239.35)." (FOLLESDAL, 1969, p. 681) É interessante que o comentador evidencia a relação entre noema (vivência noemática) e a teoria da significação de Husserl, o que aparece claramente nas Idéias I. Contudo, para Follesdal: "O noema é uma entidade intencional, uma generalização da noção de significado (Sinn, Bedeutung).” (FOLLESDAL, 1969, p. 681) O autor aproxima a teoria do significado das Investigações Lógicas (1900) com a teoria bem estruturada da noese-noema nas Idéias I, e ainda cita um manuscrito não publicado de Husserl intitulado Noema und Sinn (FOLLESDAL, 1969), do qual o autor retira algumas afirmações sobre a relação noema e sentido, mas o texto de base é sem dúvida as Idéias I. Para definir a noção de sentido ou significado recorda-se aqui o famoso exemplo dado por Husserl em Idéias I §89: "A árvore pura e simples pode pegar fogo, pode ser dissolvida em seus elementos químicos etc. Mas o sentido - o sentido desta percepção, que é algo necessariamente inerente à essência dela - não pode pegar fogo, não possui elementos químicos, nem forças, nem qualidades reais." (HUSSERL, 2006, p. 206) Aparece, portanto, aqui outra relação importante, a definição de que todo noema tem seu significado (sentido), e o significado é a essência da vivência intencional.
} 
1987, p. 99) A consciência transcendental é vazia de conteúdo, as coisas, as imagens, as memórias não estão na consciência, como que armazenadas num computador, elas são à consciência, estão em direção relacional com a mesma.

O artigo é relevante por apresentar uma nova perspectiva em relação à compreensão da música se comparada aos comentários existentes. Dentre eles destacam-se: A imaginação segundo Husserl de Maria Manuela Saraiva, Música e imaginação em 'Lições sobre a consciência imanente do tempo' de Husserl de José Luiz Furtado. Tais comentários trazem uma perspectiva limitada da fantasia para Husserl, por não analisarem o volume XXIII da husserliana intitulado: Fantasia, consciência de imagem e memória.

O objetivo do texto é demonstrar a importância do volume XXIII para um entendimento correto da música como obra de arte intuída pela fantasia na temporalidade modificada da presentificação caracterizada pelo tempo futuro. Trata-se de provar que a memória, a percepção e o passado pouco podem fazer para construir uma apreensão de melodia como uma consciência de música, sem a referência ao fantasiar e ao futuro, ou seja, não se pode afirmar o fenômeno da música sem afirmar a existência temporal de novas representações, no caso de novas presentificações/Vergegenwärtigungen.

\section{A MÚSICA NAS LIÇÕES DO TEMPO}

A análise detida da obra Lições do tempo é de suma im-

\footnotetext{
${ }^{7}$ Abreviação da obra Lições para uma fenomenologia da consciência interna do tempo de Edmund Husserl publicada em 1905.
} 
portância para se pensar a música como fenômeno intuído fantasticamente. Nas Lições do tempo trata-se de determinar em qual tempo da consciência a música se apresenta, ou seja, como é possível ouvir uma melodia na perspectiva fenomenológica. A música, a melodia, só é ouvida de forma completa e com sentido se a relação temporal da consciência pura estiver relacionada com suas presentificações mnemónicas e fantásticas. A continuidade temporal e também a apreensão da continuidade musical só tem sentido se a temporalidade do futuro estiver conectada com o passado e o presente. Por isso, o tempo futuro dado pela fantasia é a chave de acesso ao campo da intuição musical.

Para demonstrar a fantasia e o futuro com modos mais apropriados para captar a melodia através da consciência temporal, deve-se primeiramente retomar algumas teses iniciais da obra Lições do tempo. Já no primeiro parágrafo da obra tem-se uma separação fundamental para pensar a temporalidade na fenomenologia. A exclusão do chamado tempo objetivo faz surgir o chamado "tempo imanente do curso da consciência” (HUSSERL, 1994, p. 39), é este o tempo fenomenológico ${ }^{8}$, ou seja, o tempo pensado a partir de uma consciência reflexiva. Husserl define o tempo objetivo como tempo real e tempo do mundo. Diz:

Tal como a coisa real, o mundo real não é um dado fenomenológico, como também não o é o tempo do mundo, o tempo real, o tempo da natureza no sentido das ciências naturais e também da psicologia, como ciência natural do psíquico. (HUSSERL, 1994, p. 38).

\footnotetext{
${ }^{8} \mathrm{O}$ tempo fenomenológico é o tempo da consciência pura, não o tempo de qualquer consciência (como a consciência psicológica), mas da consciência reduzida fenomenologicamente.
} 
O tempo objetivo deve ser excluído como se fosse feita uma redução fenomenológica do tempo da experiência real, e restasse como resíduo o tempo imanente, ou seja, "...o tempo que aparece [erscheinende Zweit], a duração que aparece como tal", ou seja, que aparece à consciência pura. (HUSSERL, 1994, p. 38) De fato, Husserl não se demora na explicação do que seria o tempo objetivo. Nas Lições do tempo simplesmente fala de um "tempo do mundo objetivo" (HUSSERL, 1994, p. 38-39), e que mesmo o tempo da consciência psicológica deve ser excluído, pois se trata do "tempo objetivo de uma vivência" (HUSSERL, 1994, p. 38). Assim, Husserl faz uma divisão do tempo em: tempo objetivo real, tempo da consciência psicológica e tempo da consciência fenomenológica, ou também chamado de tempo imanente do curso da consciência. (HUSSERL, 1994). Para tornar mais claro o que seria o tempo objetivo Husserl o define como tempo do mundo ${ }^{9}$ caracterizado pela "existência de uma duração cousal [dinglichen Dauer]". (HUSSERL, 1994, p. 38) Torna-se primordial ressaltar aqui que Husserl nos seus primeiros escritos sobre o tempo de 1905, ainda não tinha constituída a tese das reduções fenomenológicas, tais aparecem mais claramente nas Idéias $I^{10}$

\footnotetext{
${ }^{9} \mathrm{Na}$ obra Idéias para uma fenomenologia pura e uma filosofia fenomenológica (A tradução em português brasileiro da obra foi publicada antes do acordo ortográfico com Portugal, por isso, a palavra ideia está acentuada) há uma explicação para o tempo do mundo, ele chama de tempo cósmico, no $§ 81$ trás uma análise sobre o tempo cósmico da realidade material não ter perdido o vinculo com o tempo das vivências da consciência, e que estas não são medidas pela posição do sol, do relógio e de nenhum meio físico. (HUSSERL, 2006) Pode-se deduzir daqui a definição de tempo objetivo como tempo do mundo físico, o tempo do relógio por assim dizer.

${ }^{10}$ Abreviação da obra Idéias para uma fenomenologia pura e uma filosofia fenomenológica. Na obra Idéias I, as reduções fenomenológicas formam o capítulo IV da segunda seção. Primeiro Husserl explica que a redução é ampliada à toda atitude natural, e ao mundo natural. Este é o mundo físico Cont.
} 
de 1913.

$\mathrm{Na}$ sequência do texto das Lições do tempo, isto é, depois que se estabelece o tipo de temporalidade a ser tratada fenomenologicamente, o tempo imanente da consciência, Husserl introduz sua primeira colocação sobre a música. Diz: "Que a consciência de um processo sonoro, de uma melodia que agora ouço, mostre uma sucessão, acerca disto temos uma evidência que faz aparecer qualquer dúvida ou negação como destituída de sentido”. (HUSSERL, 1994, p. 39) Husserl relaciona a apreensão da música à consciência imanente do tempo fenomenológico e não do tempo real objetivo. A sucessão só existe para uma consciência na qual a melodia apareça através da formação de uma intencionalidade fantástica.

Sobre a sucessão temporal aplicada ao exemplo da música, Husserl continua dizendo:

Quando, por exemplo, soa uma melodia, o som individual não desaparece completamente com o cessar do estímulo ou então com o movimento dos nervos por ele excitados. Quando soa o novo som, o precedente não desaparece sem deixar rastro, senão nós seríamos mesmo incapazes de notar as relações entre os sons consecutivos; nós teríamos, em cada instante, um som, eventualmente, no intervalo de tempo entre o toque de dois sons, uma pausa vazia, porém, a representação de uma melodia. (HUSSERL, 1994, p. 45).

O som passado individual não desaparece com sua passagem no tempo, ou seja, é preciso que a memória ${ }^{11}$ entre

\footnotetext{
e psicofísico. Ela é o meio metódico que possibilita o acesso ao campo da consciência transcendental. Primeiro se reduz o mundo natural, depois o eu enquanto ser humano natural, depois a transcendência de Deus, e exclusão das disciplinas eidéticas materiais. A redução exclui toda orientação dogmática do conhecimento (HUSSERL, 2006).

${ }^{11}$ A memória ou também chamada recordação é um ato intencional da consciência, no caso da consciência do tempo ela pode ser chamada também de uma presentificação.
} 
em cena para garantir a apreensão da música em sua integralidade. Sobre a influência da memória na construção da temporalidade musical ele afirma:

Apoiada na aparição da memória momentânea, a fantasia constrói a representação do futuro num processo semelhante àquele pelo qual, sob certas circunstâncias, chegamos a representar certas novas espécies de cores e sons quando seguimos as relações e formas bem conhecidas. (HUSSERL, 1994, p. 48).

Nas Lições do tempo aparecem várias designações para o conceito memória. No $\S 4$ tem-se a memória momentânea [Momentangedächtnisses] (HUSSERL, 1966, p. 13). Já no § 14 que trata da reprodução de objetos temporais, faz-se uma distinção entre recordação primária e recordação secundária. A primeira é a retenção e a segunda é a recordação interativa. A recordação primária se relaciona com a percepção, já a recordação secundária se relaciona com a fantasia. Define-se assim a recordação primária: "Caracterizámos a recordação primária ou retenção como uma cauda de cometa, que se agrega a respectiva percepção" ${ }^{12}$. (HUSSERL, 1994, . 67) Deve-se ressaltar que Husserl usa dois termos em alemão para designar a memória, o primeiro é gedächtnisses, que se traduz por memória e Erinnerung ${ }^{13}$ traduzido para o português como recordação e ou lembrança. No parágrafo da citação acima ele usa o termo Erinnerung que foi bem vertido ao português com a palavra recordação, tradução feita por Pedro M. S. Alves para Portugal. Ainda é preciso

\footnotetext{
${ }^{12}$ No original está escrito: "Wir bezeichneten die primäre Erinnerung oder Retention als einen Kometenschweif, der sich na die jeweilige Warnehmung anschließt" (HUSSERL, 1966, p. 35. Grifo nosso)

${ }^{13}$ ERINNERUNG. In: Langenscheidts Taschenwörterbuch Portugiesisch. Berlin und Müchen, Langenscheidt KG, 1968, p. 789.
} 
definir a recordação secundária, sobre esta afirma ser a presentificação na base de fantasias, ou seja, trata-se de presentificações de um modo auto-suficiente e que ocorrem sem agregação de percepções. (HUSSERL, 1994) Ele cita um exemplo de recordação secundária: "Consideremos um caso de recordação secundária: recordamo-nos, digamos, de uma melodia que ouvimos recentemente num concerto". (HUSSERL, 1994, p. 67) Neste caso, a memória corresponde a um "ponto-agora da recordação" (HUSSERL, 1994, p. 67), apesar do auxilio da recordação a melodia é ouvida graças a presentificação de fantasia.

A sucessão temporal é dada pela relação de modificação da vivência presente, que cai no passado e se lança ao futuro. A apreensão perceptiva de um som é modificada numa presentificação de memória e de fantasia para virar uma melodia completa. $\mathrm{O}$ novo som ao surgir na corrente temporal aparece como vivência da fantasia.

A vivência perceptiva da música não sobrevive sem a nova presentificação (representação) fantástica. Diz Husserl:

É, por conseguinte, uma lei universal que, a cada representação dada, se ligue, por natureza, uma cadeia contínua de representações, da qual cada uma reproduz o conteúdo da precedente, mas de tal maneira que ela fixe sempre à nova um momento do passado. (HUSSERL, 1994, p. 46. Grifo nosso).

O grifo da palavra reproduz é para destacar que a representação reprodutiva é limitada ao passado e ao perceber. $\mathrm{O}$ destaque da palavra nova, que se refere à nova representação fixada ao momento passado, tem haver com a nova representação de fantasia. Esta não é uma simples reprodução ou cópia da percepção, mas uma nova representação, uma fantasia produtiva, criadora. No caso específico da música a 
fantasia é produtiva. Explica Husserl ao falar do exemplo da melodia:

Assim, a fantasia (Phantasie produktiv) mostra-se aqui, de um modo peculiar, produtiva. Trata-se aqui do único caso onde ela cria um momento das representações verdadeiramente novo, a saber, o momento do tempo. Assim, descobrimos no campo da fantasia a origem das representações de tempo. (HUSSERL, 1994, p. 46. Grifo nosso).

No caso da arte, em especial da música, a fantasia é criadora e não depende da percepção como base de cópia para uma vivência fantástica. Esta citação prova que Husserl inova no conceito de fantasia, e que este difere sim da tradição filosófica e psicológica anteriores à fenomenologia. Nega-se também a afirmação do professor José Luiz Furtado que diz: "Desta forma a imaginação depende da percepção e lhe é inferior, pois só a percepção constitui uma doação propriamente falando originária, enquanto a imaginação é derivada da primeira”. (FURTADO, 2013, p. 18) Ora, não são em todos os casos que a "imaginação" ${ }^{14}$ depende da percepção como mostra a citação acima, mas Husserl escreve as Lições do tempo em 1905, então ainda avançará muito mais na sua compreensão da fantasia como mostra o volume XXIII da husserliana.

Para mostrar o avanço e desenvolvimento original do conceito de fantasia diante da tradição filosófica, apresenta-

\footnotetext{
${ }^{14} \mathrm{Na}$ verdade Husserl usa o termo Phantasie para falar da imaginação livre e consciência de imagem (Bildbewusstsein), por um tempo curto, para falar de imaginações dependentes da percepção. Contudo, a terminologia domimante não é imagination, mas Phantasie. Tal termo aparece já no título do volume XXIII da husserliana, a saber: Fantasia, consciência de imagem e memória. O termo fantasia diferente de imaginação, já passa uma novidade ao pensar essa intencionalidade na contemporaneidade, tal diferença terminológica se estende à conceituação, a qual mostra a novidade da fantasia e seu desprendimento da percepção e do real.
} 
se aqui a ampliação da tarefa da fantasia no arcabouço total da fenomenologia. Nas Idéias I, mais especificamente no $\S$ 70, Husserl deixa claro que a fantasia não é mera cópia da realidade, mas antes é um fundamento essencial da construção de sua "ciência de essências"15. Em duas passagens complementares vê-se a novidade e o peso da fantasia no desenvolvimento desta nova ciência. Na primeira passagem diz:

$\mathrm{Na}$ fenomenologia, assim como em todas as ciências eidéticas, existem razões em virtude das quais as presentificações e, para ser mais exato, as livres fantasias conseguem uma posição privilegiada em relação às percepções, e isso mesmo na própria fenomenologia das percepções, com exceção, naturalmente, da fenomenologia dos dados de sensação (HUSSERL 1998, p. 158-159) ${ }^{16}$.

$\mathrm{Na}$ segunda e principal citação acerca da excelência da fantasia na fenomenologia, tem haver com a concepção do "idealismo transcendental" ${ }^{7}$ defendida por Husserl em vários escritos. Diz:

\footnotetext{
${ }^{15}$ Husserl define a fenomenologia como ciência de essências na obra Idéias I e em especial no $§ 75$ ele diz: "No que concerne à fenomenologia, ela quer ser uma doutrina eidética descritiva dos vividos transcendentais puros em orientação fenomenológica...” (HUSSERL , 2006, p. 161)

${ }^{16}$ Destaca-se o termo livre fantasias, pois é usada aqui a tradução do Inglês, pois traduz melhor o termo Phantasie do alemão. A tradução de Márcio Suzuki deixa a desejar nesse ponto, pois traduz Phantasie por imaginação, o que não permite mostrar a novidade da fantasia husserliana já presente na terminologia empregada.

${ }^{17} \mathrm{O}$ tema do idealismo transcendental da filosofia de Husserl é um tema complexo e com muitas discussões, apenas cita-se uma das falas dele nesse sentido: "Desenvolvida nesta concreção sistemática, a Fenomenologia é, eo ipso, Idealismo Transcendental, se bem que num sentido fundamental essencialmente novo; não no de um idealismo psicológico, nem no de um Idealismo que, a partir de dados sensuais carecidos de sentido, quer derivar um mundo pleno de sentido. Ela não é também um Idealismo kantiano, que, pelo menos como conceito-limite, crê poder manter em aberto a possibilidade de um mundo de coisas-em-si. Ela é, antes, um idealismo que não consiste em nada mais do que na auto-explicitação, consequentemente desenvolvida, do meu ego enquanto sujeito de todo o conhecimento possível, na forma de uma ciência egológica sistemática, e isto a respeito de cada sentido de ser com o qual tudo o que é deve poder ter para mim, o ego, precisamente um sentido." (HUSSERL, 2010, p. 128)
} 
Assim, para quem gosta de expressões paradoxais e entende a plurivocidade do sentido, pode-se realmente dizer, com estrita verdade, que a 'ficção' constitui o elemento vital da fenomenologia, bem como de todas as ciências eidéticas, que a ficção é a fonte da qual o conhecimento das "verdades eternas" tira seu alimento. (HUSSERL, 1994, p. 154).

A ficção como elemento vital da fenomenologia é a vivência noemática correspondente à vivência noética da fantasia. Refuta-se com tais citações a ideia da percepção ser superior a fantasia, como diz a interpretação estabelecida por Maria Manuela Saraiva e copiada por José Luiz Furtado, que diz:

Mas a forma mais plena e originária de intuição é a percepção sensível, de modo que a imaginação estará condenada a ocupar um lugar secundário na hierarquia dos modos de consciência, como já ocorria na tradição filosófica anterior, seja nas correntes empiristas ou racionalistas. (FURTADO, 2013, p. 18).

Neste mesmo sentido, pensa-se a leitura de Saraiva como equivocada por quatro pontos principais, os quais a maioria dos comentadores repetem. Trata-se de início da leitura do primado da percepção em detrimento da fantasia, o qual não se sustenta numa leitura mais atenta, como foi mostrado acima. Saraiva diz que: "Poder-se-ia dizer que esta teoria, tomada no seu conjunto, constitui uma confirmação evidente da tese principal da fenomenologia de Husserl, a saber, o primado da percepção”. (SARAIVA, 1994, p. 269). Um segundo ponto a ser notado é a ausência do uso do volume XXIII da Husserliana, que apareceu em 1980 em alemão, mas só foi traduzido para o francês em 2002. O terceiro ponto é a interpretação da fenomenologia de Husserl sem mencionar o idealismo transcendental. 
Como quarto ponto interessante é a comparação com a teoria da imaginação de Sartre, que se preocupa mais com a distância da psicologia e teorias do signo, do que em construir uma leitura totalizante da fantasia como primado metodológico e temporal da consciência.

Por tudo isso, pode-se ainda pensar que Husserl não tenha promovido uma renovação no conceito de fantasia perante a tradição filosófica e psicológica? Evidentemente não é mais possível aceitar a doutrina husserliana da fantasia como dependente da percepção, ou como secundária no desenvolvimento geral de sua exposição filosófica. Se não é possível aceitar a interpretação limitada da fantasia de Husserl, também não se pode pensar na música como uma arte que imita o real. Como faz Saraiva citado por Furtado: "o artista não se afasta do real senão para imitá-lo e o espectador não comtempla senão para regressar ao real" (FURTADO, 2013, p. 20). Ora, tal afirmação não se sustenta, pois a arte é sim modo de criação próprio de uma consciência fantástica, a música criada por Mozart ou Beethoven, existem como quase-presente, não existem sem uma consciência fantástica para as compreender. Elas não imitam nada, elas são criações do gênio artístico, e mesmo uma consciência não "genial" também pode criar, afinal onde está na realidade o centauro tocando flauta? Alguém o viu na realidade perceptiva? Não, por que ele é uma criação da fantasia, uma nova intenção temporal, uma nova forma de olhar o mundo, através da neutralidade da posição de existência.

Nas Lições do tempo, no $§ 14$ sobre a reprodução de objetos temporais, ou recordação secundária, Husserl iguala a fantasia a essas recordações, contudo, ele parece hesitar ao 
falar da fantasia, pois a mesma aparece em separado no $\S$ 19 sobre a diferença entre retenção e reprodução. Este último ele faz a distinção entre recordações primárias, secundárias e fantasia. Husserl diz no § 14:

...a percepção atual constitui-se como presentação (Präsentation) na base de sensações; a recordação primária, como re-presentação (Repräsentation), como presentificação (Vergengenwärtingung), na base de fantasias. Ora do mesmo modo que as presentificações se agregam imediatamente às percepções, podem também ocorrer presentificações de um modo auto-suficiente, sem agregação às percepções, e isto será a recordação secundária. (HUSSERL 1994, p. 67).

$\mathrm{O}$ interesse nessa passagem está justamente em associar a fantasia ao modo de presentificação auto-suficiente, que significa sem agregação das percepções, independente da percepção e do real. No trecho acima, Husserl chama essa intencionalidade de recordação secundária, contudo é fato que ele quer dizer aqui fantasia.

A sequência do $\S 14$ traz novamente o exemplo da melodia como intuída pela fantasia. Diz: "Percorremos a melodia na fantasia, 'como que' ouvimos inicialmente o primeiro som, depois o segundo e assim sucessivamente" (HUSSERL 1994, p. 67). Apesar do receio de Husserl em afirmar a fantasia como distante da recordação, neste trecho em particular, entra em cena a importância dos exemplos da música como forma de validar a fantasia produtiva. As Lições do tempo em especial são datadas de 1905, e os textos do período posterior anexados no volume XXIII mostram mais tranquilamente essa teoria da fantasia independente da percepção e do real. Na verdade a primeira vez que Husserl escreve sobre a fantasia é em um manuscrito de 1898 anexado do volume XXIII. Este manuscrito 
traz a separação entre fantasia e representação em imagem, este último termo se transformará em consciência de imagem até 1905. Segundo Pedro Alves, o conceito de consciência de imagem encontra seus limites e cai em desuso quando Husserl se depara com o tema do tempo:

Mas bastará apenas que Husserl, entre 1901 e 1904, se abeire dos problemas específicos da consciência do tempo por força da dilucidação das diferenças internas do fenômeno da presentificação para que a estrutura da consciência de imagem comece a revelar suas limitações para uma descrição da essência da recordação e, a partir daí, para a determinação da própria essência dos atos presentificadores em geral. (ALVES, 2003, p. 80).

Deve-se retomar a análise detida das Lições do tempo para pensar um pouco mais nos exemplo que aparecem sobre a música e sua conexão com a temporalidade. Entre o já citado $\$ 19$ das Lições do tempo e o $\$ 20$ ocorre uma grande diferença terminológica e conceitual. $\bigcirc \$ 19$ foi escrito em 1905 e tem claramente uma relação forte entre percepção, recordação e fantasia. No $\$ 20$ ocorre o reconhecimento de uma consciência reprodutiva que atua na liberdade do fluxo temporal, contudo o $\$ 20$ foi escrito com base num esboço de 1911. O emblemático $\$ 19$ cita Brentano acerca da apreensão do tempo, o qual julgou vir da fantasia. Husserl aparentemente refuta tal posição conceitual ao dizer que: "Fantasia é a consciência caracterizada como presentificação (reprodução). Há, com certeza, tempo presentificado, mas este reenvia necessariamente ao originalmente dado, não fantasiado, mas sim presentado [präsentierte].” (HUSSERL 1994, p. 75).

Essa passagem do texto faz parecer que Husserl não pensa a fantasia como importante na apreensão temporal 
feita pela consciência, contudo entende-se essa oscilação entre a percepção, como forma constituinte originária e a fantasia como intencionalidade livre, diferença da própria construção intelectual da fenomenologia que permite pensar as duas intencionalidades como importantes, cada uma dentro do seu contexto teórico. No caso da percepção e do presente tem-se uma consciência do agora. $\mathrm{O}$ exemplo musical dado por Husserl é: "Ouvimos à volta de dois ou três sons e temos, durante a extensão temporal do ato, uma consciência do som agora mesmo ouvido" (HUSSERL 1994, p. 76). Conforme diz Husserl essa consciência é sempre a mesma, seja no presente, seja na retenção recordativa. A consciência do som no agora depende dessa passagem do passado ao presente, da recaída do som no passado e a retenção para o presente através da presentificação recordativa.

A fantasia aparece logo na sequência no mesmo $\$ 19$, a sucessão de uma intenção continua dirigida para que o som mesmo agora ouvido se reproduza ainda uma vez, neste caso presentifico o compasso do agora ouvido mais uma vez e ele se reproduz. Diz Husserl: "Na presentificação, temos agora uma vez mais o som ou a forma sonora juntamente com sua extensão temporal total.” (HUSSERL 1994, p. 76). $\mathrm{Na}$ presentificação se estende o som fase por fase, a partir disso pode ocorrer uma reprodução simples ou uma reprodução de reprodução. Ele fala de fantasia quando fala da presentificação de um soar do som. Sobre os correlatos intencionais da fantasia tem-se a explicação dos fantasmas. Nesse exemplo do som, os fantasmas que apresentam o som não ficam paralisados na consciência, mas: “...modifica-se antes de um modo peculiar e funda a consciência presenti- 
ficante da duração, alteração, subsequência, etc." (HUSSERL 1994, p. 76-77).

Husserl utiliza reprodução para falar de fantasia, como fica claro nesse trecho do §19: "Cada percepção concreta implica todo um continuo de tais matizes. E também a reprodução, a consciência de fantasia, pede precisamente as mesmas matizações, só que reprodutivamente modificadas." (HUSSERL 1994, P. 77). O decurso do fluxo temporal e o decurso da melodia dependem necessariamente da fantasia como forma de reprodução ${ }^{18}$. A fantasia é um tipo de presentificação livre, nesta forma de intencionalidade tem-se a continuidade da melodia pela ação livre do ato da consciência fantástica. O \& 20 que se baseia num manuscrito de 1911, ou seja, posterior a 1905, data das Lições do tempo. Importa destacar a mudança de perspectiva frente ao conceito de fantasia, que no $\S 20$ aparece como presentificação. Segundo Husserl nesse parágrafo:

[...] a presentificação é qualquer coisa de livre, é um livre percorrer; podemos efetuar a presentificação 'mais depressa' ou 'mais devagar', distinta e explicitamente ou então confusamente, com rapidez do relâmpago, num só traço, ou em passos articulados, etc. A presentificação é, neste caso, ela própria um acontecimento da consciência interna e tem, como tal, o seu agora atual, os seus modos de decurso, etc. (HUSSERL 1994, p. 78).

Para validar passagem acima, destaca-se a citação que diz: "Na simples fantasia, não há nenhuma posição de agora reproduzido e nenhuma coincidência do mesmo com um

\footnotetext{
${ }^{18}$ Husserl coloca dois termos para falar da fantasia. No início das Lições ele diz que há uma fantasia produtiva, depois, em especial nesse $\S 19$ ele fala da fantasia como reprodução, o que a coloca em proximidade com a recordação. Contudo, conforme o volume XXIII e os textos posteriores a 1905, a fantasia tem o caráter de criação e não de reprodução.
} 
agora do passado." (HUSSERL 1994, P. 80). A fantasia é uma presentificação livre e isso se caracteriza pela sua liberdade de passar de uma posição a outra, como no exemplo da música. Cada som advém, ou seja, avança no futuro, por causa dessa liberdade de variação da fantasia. Um som depois do outro só formam uma perfeita harmonia auditiva, ou uma bela sinfonia, com a presença da fantasia, que não dependem da recordação, seja ela primária ou secundária, como explicou Husserl no $\S 19$. A diferença entre as duas seria a distancia com a percepção, e nessa distância estaria a diferença entre um agora reproduzido e um agora do passado. A música flutua entre a percepção, como consciência que reconhece a melhoria no momento presente, e a presentificação que seria uma atualização do som passado e do som futuro.

Com um exemplo da música pode-se compreender esta relação entre fantasia e recordação. Como explica Husserl:

Se reproduzo uma melodia ouvida, então o agora fenomênico da recordação interativa presentifica um passado: na fantasia, na recordação interativa, soa agora um som. Ele reproduz, digamos, o primeiro som da melodia, que é uma melodia passada. (HUSSERL 1994, p. 80).

A citação acima faz pensar que a fantasia seria um tipo de recordação, contudo, é claro que Husserl está confuso com o uso do próprio termo fantasia, e assim, nesse $§ 23$ faz a distinção entre recordação interativa e fantasia. Como explica a husserliana, há uma diferença de datas no texto, uma parte do texto baseia em esboço dos anos 1907-1909 ${ }^{19}$.

\footnotetext{
${ }^{19}$ Conforme nota 41 da tradução portuguesa das Lições do tempo: 'O texto da primeira metade do $\S 23$ (do início até “...pode-se efectuar apenas na consciência original do tempo".) baseia-se na foCont.
} 
Contudo, a sequência do texto, apesar das mudanças feitas por Husserl, mostra a fantasia como independente da recordação e do agora reprodutivo.

No $\S 30$ Husserl fala da modificação retencional da consciência temporal, contudo numa passagem ele deixa claro que é preciso mais do que a percepção e a memória para "construir" uma consciência nova do agora.

Dito fenomenologicamente: a consciência do agora, que se constitui com base na matéria A, transforma-se constantemente numa consciência de passado enquanto, ao mesmo tempo, se constrói uma sempre nova consciência do agora. (HUSSERL 1994, p. 90. Grifo nosso).

A intencionalidade capaz de construir uma nova consciência do agora é a fantasia, que se caracteriza pela criação de novas imagens ou fantasmas. Grifa-se a palavra constrói do alemão aufbaut que indica a função de edificar as novas consciências de agora, tal papel só pode ser feito pela fantasia.

No exemplo do som ocorre que a caída ao passado precisa necessariamente de um auxílio da fantasia para recolocar, ou melhor, presentificar o novo som agora presente à consciência. Torna-se evidente que a fantasia constrói o fluxo temporal e que no caso da música o som também depende do tempo. "O som constrói-se no fluxo temporal através das suas fases" (HUSSERL 1994, P. 92). Isso significa ser a consciência do tempo e a apreensão da música uma relação entre percepção e fantasia, seguidas pela presentifi-

lha 44 do manuscrito das lições de 1905. O texto da segunda metade do parágrafo baseia-se na folha de um esboço surgido, verossimilmente, entre 1907 e 1909, o qual é reproduzido, na sua forma original e completa, nos textos complementares, n. ${ }^{\circ} 45$; particularmente pp. [299] e [300]. Nota da Hua. (HUSSERL 1994, P. 80). 
cações da memória que também intervém numa construção total do tempo e da melodia. Apesar de a música ser sempre submetida ao retorno do agora, na percepção, a fantasia não pode deixar de atual para que surjam novos agora.

A tese da percepção como dependente da fantasia é retomada no artigo de John Sallis. Ele cita Saraiva como exemplo de uma conclusão acerca da chamada por ela, imaginação. Sallis lembra: "Outra consciência consistiria em subordinar a imaginação à percepção. À declarar secundária, inferior à percepção" (Sallis 1989, P. 67). Segundo Sallis: "A fantasia é assim mais complexa que a percepção onde um só objeto é apreendido" (SALLIS 1989, P. 75). John Sallis consultou os manuscritos de Husserl que originaram o volume XXIII da husserliana, portanto tinha uma visão mais favorável acerca da fantasia. Como ele diz no final de seu artigo:

"Talvez nos poderíamos, então, começar a compreender o poder da imaginação de abrir a fenomenologia. E portanto, em se parando ao poder que a fenomenologia tem de abrir a imaginação, nos teríamos começado a desnudar as solidariedades mais fortes e mais profundas da fenomenologia" (SALLIS 1989, p. 88).

Para Sallis, a fantasia abre um campo mais profundo da fenomenologia. A música pensada fenomenologicamente se apresenta como exemplo mais perfeito e claro dessa profundidade de pensamento, que relaciona a consciência do tempo com a presentificação de fantasia.

Há outro aspecto importante da fantasia que aparece nas Lições do tempo de modo quase disfarçado. Trata-se da característica já citada nesse artigo, da consciência de fantasia construir novos agora, ou ainda de criar novos sons. Husserl fala disso no $\$ 33$ e desse modo: 
Pertence a essência à priori do tempo que ele seja uma continuidade de posições temporais - preenchidas uma vezes com objetividades idênticas, outras, com variáveis - e que a homogeneidade do tempo absoluto se constitua inexoravelmente no fluxo das modificações de passado e no constante jorrar de um agora, o ponto temporal criador, o ponto-fonte da posição temporal geral. (HUSSERL 1994, p. 98. Grifo nosso).

A criação no tempo só é possível graças ao movimento permitido pela consciência de fantasia, a chamada presentificação de fantasia. Ela tem o poder de criar e fazer fluir o tempo fenomenológico, a consciência interna do tempo. Este aspecto criador da fantasia a coloca como fundamental para pensar a arte e a música. A criação aparece mais claramente no volume XXIII da husserliana.

\section{2) FANTASIA E "COMO SE": A MÚSICA NO VOLUME XXIII DA HUSSERLIANA}

A música aparece no volume XXIII, mas para compreender a sua atuação nessa obra, deve-se pensar o papel da neutralidade e da redução um pouco antes, nas origens do conceito de redução. Na obra A ideia da fenomenologia de 1907, Husserl se pergunta acerca da relação entre fantasia e redução:

Percepcionando a cor e exercitando a redução, obtenho o fenômeno puro de cor. E se agora levo a cabo uma pura abstração, obtenho assim, a essência de cor fenomenológica em geral. Mas, não estou eu também na plena posse desta essência, quando tenho uma fantasia clara? (HUSSERL 1987, p. 97).

É no volume XXIII que a teoria da neutralidade fica clara, e além dela a relação da fantasia com sua característica própria a criação livre. Fala-se também da relação entre 
música, tempo e fantasia de maneira mais clara e específica. Diz Husserl:

Nós vivemos na neutralidade, nós não reunimos, cara a cara na intuitividade, nenhuma posição efetiva, tudo isso que chega ali adiante, isto que está ali nas coisas e nas pessoas, tudo o que é dito, tem o caráter do como se". (HUSSERL 2002, p. 487).

A vivência da fantasia se dá no modo do como se, assim as obras de arte são captadas no como se, na irrealidade, como ficção livre. A modificação de neutralidade inibe toda crença na posição de existência do mundo. Coloca a crença em suspenso e faz surgir um mundo irreal. $O$ trecho mais expressivo sobre a música estar relacionada à fantasia foi escrito entre 1916 e 1918. Trata-se do apêndice LIX (59) da husserliana XXIII, que fala sobre a teoria da arte para Husserl. Ele faz uma divisão entre a arte plástica e a arte puramente fantástica. Esta divisão remete ao seu conceito, que caiu um desuso, de bildbewustsein ou consciência de imagem para falar de arte plástica e phantasie para falar de arte puramente fantástica. Segundo Husserl:

Toda arte evolui sobre dois extremos: a) Arte plástica: figurando em imagem, reproduzindo em imagem-cópia por intermediário de uma consciência de imagem. b) Arte puramente fantástica, produzindo as configurações de fantasia na simples modificação de neutralidade. Não produzindo nenhum caráter de imagem concreto. $\mathrm{O}$ 'era uma vez" se refere ainda ao agora atual e ao mundo, e o conflito com eles pode indicar um caráter de imagem que não constitui todavia um objeto-imagem intuitivo. Música. Fantasia lúdica. (HUSSERL 2002, p. 509$)^{20}$.

A arte puramente fantástica é pura por estar no modo

\footnotetext{
${ }^{20} \mathrm{O}$ apêndice LIX tem data provavelmente entre 1916 e 1918.
} 
do "era uma vez", ou seja, da possibilidade e da criação. A música é o exemplo mais vivo de uma vivência intencional da fantasia. A criação da fantasia aparece no volume XXIII no apêndice LVII quando Husserl associa liberdade da fantasia de se "mover" e como isso resulta na possibilidade de criação de mundos. Somente a fantasia possui essa liberdade de fluir no tempo e criar novas presentificações. Esse aspecto criador é o elemento fundamental para a compreensão do porque a fantasia rege a música. Diz Husserl sobre o criar da fantasia:

De outro lado, fazer o criar consiste sempre também nisto que o fantasma pode não somente continuar a produzir livremente as configurações sobre o sol de um começo quase fixo, mas também transformar de maneira criadora, nisto que ela pode sempre criar novos mundos, e refundar num sentido de uma não concordância um mundo dado com um mundo já formado. (HUSSERL 2002, p. 505. Grifo nosso) ${ }^{21}$.

A citação acima faz referência a um exemplo: "eu posso me colocar sob o sol da experiência” (HUSSERL 2002, P. 503), que fala da possibilidade de pensar a experiência de se colocar ao sol na percepção e depois na fantasia. $O$ fantasma aqui é o correlato intencional da fantasia, ou seja, a fantasia é consciência de fantasma ou de elementos ficcionais. O criar aparece na citação como a forma de sair da realidade perceptiva e adentrar ao campo da fantasia e de sua irrealidade. Mostra-se aqui a amplitude da fantasia se comparada a percepção, seu quadro de descrição é muito mais vasto e mais livre que o da percepção, ou o da memória.

${ }^{21}$ O texto do apêndice LVII data provavelmente de 1917. 
A irrealidade é o ponto chave para entender o modo possível da natureza fantástica. Já explica Fink em seu texto:

O problema diretor de toda nossa pesquisa é a questão do sentido da fenomenologia da irrealidade (Unwirklichkeit). Nós não entendemos sob esse título equívoco de irrealidade um conceito oposto à realidade ao sentido de uma posição existencial realizada em juízos. Não se trata de uma análise da teoria do juízo, mas de uma tentativa de poder avançar o conhecimento das vivências elementares constituindo a irrealidade e por empreender, na segunda parte, a elucidação constitutiva. $\mathrm{O}$ 'ir' de irrealidade tem manifestamente aqui outro sentido diferente daquele de uma negação. (FINK 1997, p. 82).

A implicação entre irrealidade e neutralidade está justamente em se compreender a não negação do mundo através da vivência de fantasia, a fantasia não quer negar o mundo, ou o real, a fantasia como irrealidade pretende antes estabelecer uma neutralidade em relação ao ser do mundo real, isso significa, não afirmar e nem negar, mas apenas ser neutro quanto a posição de existência. A fantasia é neutra em comparação com o mundo dos fatos (real), contudo seu mundo é o mundo das possibilidades irreais, no sentido que Husserl explica na introdução das Ideias I quando diz que a fenomenologia estuda os fenômenos irreais, ou seja, os fenômenos de essência. (HUSSERL 2006).

A música aparece como arte mais vigorosa para se aproximar da fenomenologia enquanto ciência, pois a ficção é o elemento vital da fenomenologia, como Husserl mesmo diz nas Idéias I § 4 intitulado visão de essência e fantasia. Diz:

O eidos, a essência pura, pode exemplificar-se intuitivamente em dados da experiência, tais como percepção e recordação, etc, mas igualmente também em meros dados da fantasia. (HUSSERL 1998, p. 11). 
No $\S 4$ de Ideia I Husserl ainda afirma que com a livre fantasia produzimos figuras no espaço, melodias, processos sociais e podemos por ideação neles apreender essências puras, as vivências fantásticas, como a música, podem ser captáveis em sua essência pura, ou seja, em seu sentido original. E para Husserl: "É indiferente, neste caso, se algo assim já tenha sido dado ou não numa experiência atual". (HUSSERL 1998, P. 11) A música como exemplo de vivência de fantasia, como presentificação produtiva do tempo em novas apreensões de som e como arte puramente fantástica e ficcional, tem como pressuposto fenomenológico a neutralidade, e ainda a pura intuição (visão) de essências (Wesenserschauung) que se apreende mais facilmente através da fantasia.

\section{CONCLUSÃO}

A música como apareceu nas Lições do tempo, é vivência fantástica de lançar-se ao futuro, e conforme as análises do volume XXIII, a fantasia rege a arte puramente ideal, a música e a fantasia lúdica, esta última seria a arte de criar histórias, mitos e seres peculiares.

As Lições do tempo de 1905 marcam o desaparecimento do conceito de consciência de imagem e a nova perspectiva de compreender a fantasia através da temporalidade, possibilidade essa expressa pelo conceito de presentificação. A fantasia e a memória são presentificações, contudo somente a fantasia é livre e criadora, o que permite refletir sobre a arte e a música.

Apesar da relação entre percepção e fantasia ser importante, pois a consciência temporal se dá no presente, no a- 
gora, a fantasia tem o papel de produzir novos agora, o que permite a produção do som e sua apreensão temporal.

Mostrou-se no volume XXIII a leitura da fantasia como essa consciência criadora, mostrou-se o papel dela na compreensão da obra de arte, e como Husserl vê a música na hierarquia das artes.

Pode-se afirmar que a fantasia faz compreender a melodia tocada como algo completo, como uma música de início, meio e fim, pois sem a atuação da fantasia não haveria criação do novo, e não haveria movimento de produção, ou seja, não haveria sequência musical.

Abstract: The article analyzes the question of music in the works of Edmund Husserl. Among the most important works for the theme are the Lessons for a phenomenology of internal time consciousness published in 1905 and volume XXIII of the Husserlian under the title: Fantasy, image awareness and memory. From the phenomenology of intuitive presentifications. Posthumous texts (1898-1925). The article criticizes the readings that limit the understanding of fantasy, a mode of consciousness that generates musical art.

Keywords: Temporality; fantasy; music.

\section{REFERÊNCIAS}

ALVES, M. S. Pedro. Subjectividade e tempo na fenomenologia de Husserl. Lisboa: Editora Centro de Filosofia da Universidade de Lisboa, 2003.

FINK, Eugen. De la Phénoménologie. Tradução de Didier Frank. Paris: Minuit, 1974.

FOLLESDAL, Dagfinn. Husserl's Notion of Noema. The Journal of Philosophy, v. 66, n. 20, Sixty-Sixth Annual Meeting of the American Philosophical Association East- 
ern Division, 1969, p. 680-687.

FURTADO, José Luiz. Música e imaginação em "Lições sobre a consciência imanente do tempo" de Husserl. ANAIS - Simpósio de Estética e filosofia da música SEFIM/UFRGS. Porto Alegre, v. 1, n. 1, 2013.

HUSSERL, Edmund. A ideia da fenomenologia. Porto: Edições 70, 1987.

- Idéias para uma fenomenologia pura e para uma filosofia fenomenológica: introdução geral à fenomenologia pura. Tradução de Márcio Suzuki. Aparecida (SP): Idéias e Letras. 2006.

. Ideas pertaining to a pure phenomenology and to a phenomenological philosophy. First book: general introduction a pure phenomenology. Netherlands: Kluwer Academic Publishers. 1998.

. Investigações lógicas: prolegômenos à lógica pura: volume 1. Tradução Diogo Ferrer. 1. ed. Rio de Janeiro: Forense, 2014.

- Investigações Lógicas. Segundo volume, parte 1: Investigações para a fenomenologia e a teoria do conhecimento. Lisboa: Phainomenon, 2007.

- Lições para uma consciência interna do tempo. Trad. Pedro M. S. Alves. Lisboa: Editora: Imprensa nacional-Casa da moeda, 1994.

- Meditações cartesianas. Conferências de Paris. Trad. Pedro M. S. Alves. Editora Phainomenon, 2010.

. Phantasie, Bildbewusstsein, erinnerung. Zur 
phänomenologie der anschaulichen vergegenwärtigungen. Dordrecht: Kluwer Academic Publishers, 1980.

. Phantasie, conscience d'image, souvenir. Editions Jérome Millon, Paris: 2002.

. Zur Phänomenologie des inneren Zeitbewusstesens (1893-1917). BOEHM, Rudolf (ed.). Netherlands: Martinus Nijhoff, 1966.

Langenscheidts Taschenwörterbuch Portugiesisch. Berlin und Müchen: Langenscheidt KG, 1968.

SALLIS, John. L'espacement de l'imagination. In: ESCOUBAS, Eliane; RICHIR, Marc. Husserl, Grenoble: Editions Jérome Millon, 1989, p. 65-88.

SARAIVA, Maria Manuela. A imaginação segundo Husserl. Tradução de Isabel Támen e António Pedro Mesquita. Paris: Calouste Gulbenkian, 1994.

SARTRE, Jean-Paul. A imaginação. In: Sartre coleção Os pensadores. São Paulo: Nova Cultural, 1987. 